\title{
STUDY OF THE ACTIVATING EFFECT OF INTRODUCING AIR ADDITIVES INTO THE REACTOR DURING FUEL OIL CRACKING ON COMPOSITE CATALYSTS
}

\author{
T.V. SHAKIYEVA ${ }^{\mathbf{1}}$, B.T. DOSSUMOVA ${ }^{2}$, L. R. SASSYKOVA ${ }^{\mathbf{3}}$ \& N.B. ZHAKIROVA ${ }^{\mathbf{4}}$ \\ 1,2Associate Professor, Scientific and Production Technical Center "Zhalyn” LLP, Almaty, Kazakhstan \\ ${ }^{3 *}$ Professor, Al-Farabi Kazakh National University, Almaty, Kazakhstan \\ ${ }^{4}$ Associate Professor, Al-Farabi Kazakh National University, Almaty, Kazakhstan
}

\begin{abstract}
In this research commodity fuel oil and fuel oil of the M-100 brand from the Amangeldy Gas Processing Plant (Kazakhstan) were used as cracking raw materials. The effect of adding air with different concentrations into the reaction mixture of fuel oil during the cracking on the composite catalysts was determined. Composite catalysts were prepared on the basis of natural Kazakhstan raw materials: zeolite of the Taizhuzgen deposit and clay of the Narynkol deposit. They were activated by ion exchange of sodium cations of the zeolite framework to cations of lanthanum and ammonium. It was found that the optimal for the process of cracking fuel oil at high feed rates to the reactor is a temperature of $470^{\circ} \mathrm{C}$.The yield of the kerosene-gas oil fraction during cracking of fuel oil slightly decreases with increasing volumetric feed rate. At high concentrations in the reaction mixture of air, intense gas formation begins. Therefore, air additives contribute to a deeper destruction of the hydrocarbons of the cracked feed. In the presence of air, a secondary process of symmetrical decomposition of medium-molecular hydrocarbons begins, accompanied by cyclization of the resulting hydrocarbon molecules of the gasoline fraction. The results of the research on the use of activation of cracked fuel oil by dosed injection of air into the reaction zone indicate great prospects for a new direction in the catalytic processing of heavy hydrocarbon feedstocks.

KEYWORDS: Fuel Oil, Air Additives, Catalytic Cracking, Taizhuzgen Zeolite, Narynkol Clay
\end{abstract}

Received: Jun 03, 2020; Accepted: Jun 23, 2020; Published: Jul 25, 2020; Paper Id.: IJMPERDJUN2020451

\section{INTRODUCTION}

Among the most important tasks facing the oil refining industry is the deepening of oil refining in order to obtain the maximum yield of high-quality motor fuels and raw materials for petrochemical synthesis. Limited reserves of "traditional oil" leads to the need to involve heavy and bituminous oils in the processing. However, the yield of light fractions in such oils is an insignificant part. Heavy crude oil differs from light crude in the composition and temperature of the end of boiling, characterized by a significant content of polycycloalkanes, condensed aromatic hydrocarbons and asphaltenes (Scott, 2002; Amghizar et al., 2017; Delattre et al., 2001; Occelli et al., 1984; Dadyburjor and Liu, 1993; Sassykovaet al., 2019). Processing heavy hydrocarbons is significantly more expensive due to the high coking index> 8\% (according to Conradson), a significant content of high molecular weight components - resins and asphaltenes (up to 35\%), which are enriched in heteroatoms (S, N, O) and metals, especially nickel and vanadium (up to $1000 \mathrm{~g} / \mathrm{t}$ ), which quickly deactivate catalysts for industrial catalytic and hydroprocessing processes, which imposes limitations on the quality of raw materials and eliminates its low cost (Baiseitov et al., 2017).In recent years, much attention has been paid to the development of the catalytic cracking process for processing residual types of raw materials. It is not only less expensive and more affordable, but also its 
consumption in traditional areas, except for cracking, is decreasing (Gomez and Molina, 2019; Sassykova et al., 2020; Liu et al., 2004; Pandey, 2018).The need to use a more complete load of the available catalytic cracking capacities led to the intensification of research and improvement of the cracking process of high boiling oil fractions. With an increase in the temperature of the boiling point of vacuum distillates, oil consumption decreases, and when switching to fuel oil, in addition, capital and operating costs are reduced by eliminating the vacuum distillation of fuel oil. The most rational way to ensure the economical operation of catalytic cracking units is the special preparation of raw materials (Abul-Hamayel, 2002; Tashmukhambetova, et al., 2017; Guerzoni and Abbot, 1993). Such raw materials are residues of direct distillation of oil, residues of products of distillation of thermal cracking, pyrolysis, as well as high-boiling flavored concentrates and gas oils obtained on the basis of distillate products (Redwan and All, 1992; Akhmedzhanov et al., 2012; Tulepov et al., 2018; Wada et al., 2004; Lesin et al., 2017). The fundamental approach to solving the problems of processing heavy hydrocarbon feedstocks may be the transformation of resinous-asphaltene substances, organometallic, sulfur- and nitrogencontaining compounds into compounds of other classes due to directed chemical reactions with the simultaneous disaggregation of the highest molecular weight components of heavy petroleum feedstocks (Itoh et al., 1984; Yemelyanova et al., 2019; Lesin, 2018; Rigutto et al., 2007). Traditional processes of catalytic cracking of oil residues require continuous regeneration of expensive zeolite-containing catalysts and complex instrumentation of the process. Obviously, the most promising method for producing light hydrocarbon fractions is the catalytic cracking of oil residues in an oxidizing medium, i.e. in the presence of air additives in the reaction medium.Zeolite-containing catalysts with a unique microporous structure and acid-base properties are known to catalyze the conversion reactions of $\mathrm{C}_{2}-\mathrm{C}_{7}$ paraffin hydrocarbons, turning them into valuable products of organic synthesis (Tashmukhambetova, et al., 2017; Sadeghbeigi, 2000; Ibrasheva and Zhubanov, 2000; Ibrasheva et al., 2001; Hamasaki et al., 2008; O'Connor, 2007; Omarova et al., 2019; Stocker, 2005; Tuktin et al., 2019; Brueva et al., 2001).

In this paper the effect of adding air with different concentrations into the reaction mixture of fuel oil during the cracking on the composite catalysts was researched. As cracking raw materials commodity fuel oil and fuel oil of the M100 brand from the Amangeldy Gas Processing Plant (Kazakhstan) were used. Composite catalysts were prepared on the basis of natural Kazakhstan raw materials: zeolite of the Taizhuzgen deposit and clay of the Narynkol deposit.

\section{EXPERIMENTAL}

Commodity fuel oil and fuel oil of the M-100 brand from the Amangeldy Gas Processing Plant (Kazakhstan) were used as cracking raw materials (Table 1). The fractional composition of fuel oils was determined on the basis of distillation at atmospheric and reduced pressures. The following fractions were selected: gasoline, light gas oil, vacuum gas oil and a heavy residue with a boiling point $>500{ }^{\circ} \mathrm{C}$. The content of each fraction was determined by the gravimetric method and was expressed in $\%$ of the mass. The sulfur content in fuel oils and vacuum gas oils was determined by high-temperature oxidation of samples followed by acid-base titration of the resulting sulfur dioxide. In the initial fuel oils, as well as in gasoline and kerosene-gas oil fractions obtained as a result of cracking, the presence of oxygen- and sulfur-containing compounds was determined by the IR spectral method, which, in addition, makes it possible to establish the qualitative composition of hydrocarbons in the analyzed samples.84.5 wt.\% of the weight of the fuel oil is constituted by the vacuum distillate and heavier fractions, in addition, the fuel oil contains more sulfur compared to the studied vacuum distillates (Table 1). 
Table 1: Fractional Composition and Sulfur Concentration in Commercial Fuel Oil

\begin{tabular}{|l|c|c|c|c|c|}
\hline \multicolumn{1}{|c|}{ Content, wt. \% } & Fuel Oil & Gasoline & Light Gas Oil & Vacuum Gas Oil & Heavy Residue \\
\hline Fractions & 100.0 & 0.5 & 15.0 & 44.8 & 39.7 \\
\hline Sulfur & 2.1 & - & - & - & - \\
\hline
\end{tabular}

Figure 1 shows the scheme and main flows of reagents for oxidative catalytic cracking of fuel oil.

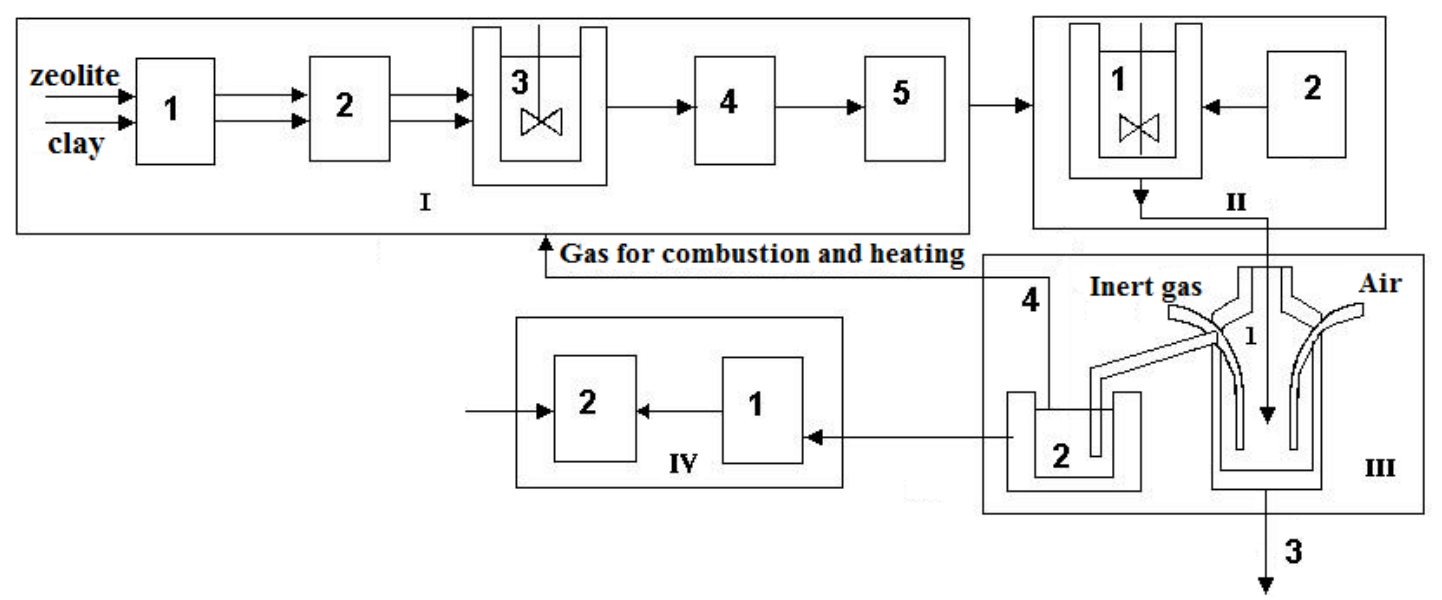

Figure 1: Schematic diagram of the catalytic conversion of fuel oil : I-catalyst preparation unit: 1-mixing unit; 2-sieves; 3-thermostatic container with agitator; 4-drying and calcination oven; 5-electromagnetic homogenizer; II - block for preparation of composite suspension in fuel oil: 1-a thermostatically controlled container with a stirrer; 2 - a reactor for electromagnetic activation of fuel oil; III-oxidative cracking unit: 1-thermostatically controlled flow reactor with systems for supplying inert gas, air and catalyst suspension in fuel oil, 2-cooled flow capacity for condensation of liquid cracking products; 3-removal of tar residue in a mixture with spent catalyst; 4 - system for dumping and burning cracking gases; IV - block for rectification of cracking products: 1-evaporation column; 2-rectification of cracking products.

The calculation of heat consumption for heating fuel oil in a cracking reactor was carried out as follows. Heat balance equation:

$$
\mathrm{Q}_{1}=\mathrm{Q}_{2}
$$

Where $\mathrm{Q}_{1}$ is the amount of heat given off by the induction heating unit per unit of time, W;

$\mathrm{Q}_{2}$ is the amount of heat perceived by fuel oil per unit of time, $\mathrm{W}$.

The heat transfer capacity is calculated using the formula:

$$
\mathrm{Q}=\mathrm{G} \Delta \mathrm{h},
$$

Where $\mathrm{G}$ is the coolant flow rate, $\mathrm{kg} / \mathrm{s} ; \Delta \mathrm{h}$-is a change in specific enthalpy, $\mathrm{J} / \mathrm{kg}$.

The change in specific enthalpy is equal to:

$$
\Delta \mathrm{h}=\mathrm{cp} \Delta \mathrm{T}
$$

The specific heat capacity of fuel oil $\mathrm{cp}$ is found in the reference book:

$\mathrm{cp}=2.7 \mathrm{~kJ} / \mathrm{kg}^{\circ} \mathrm{C}$ at average temperature:

$\left(300^{\circ} \mathrm{C}+470^{\circ} \mathrm{C}\right) / 2=385^{\circ} \mathrm{C}$

Volume of a cylindrical cracking reactor: 
$\mathrm{V}=\pi \mathrm{r}^{2} \mathrm{~h}=3.14 \cdot 0.36 \cdot 2.4=2.713 \mathrm{~m}^{3}$

Fuel oil feed rate to the cracking reactor $=2.713 \mathrm{~m}^{3} / \mathrm{h}$ or $0.0007536 \mathrm{~m}^{3} / \mathrm{s}$.

The density of fuel oil at $300^{\circ} \mathrm{C}$ is $797 \mathrm{~kg} / \mathrm{m}^{3}$, then the fuel oil consumption:

$\mathrm{G}=0.6 \mathrm{~kg} / \mathrm{s}$

Power of the induction heating unit:

$\mathrm{Q}=\mathrm{G} \cdot \mathrm{cp} \cdot \Delta \mathrm{T}=0.6 \cdot 2.7 \cdot 170=275.4 \mathrm{~W}$.

Composite catalysts were prepared on the basis of natural Kazakhstan raw materials: zeolite of the Taizhuzgen deposit (Figure 2) and clay of the Narynkol deposit.

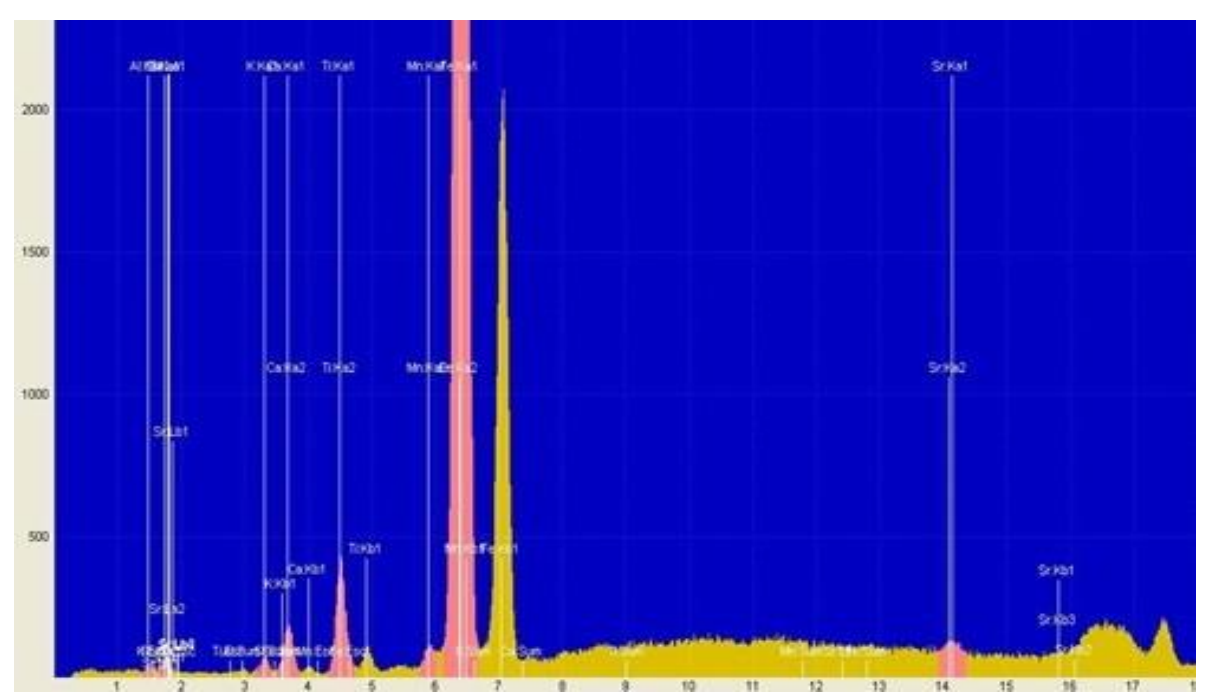

Figure 2: X-Ray Diffraction Analysis of Taizhuzgen Zeolite.

According to X-ray diffraction analysis, the presence of eight different components in the composition of Taizhuzgen zeolite (concentration, \% intensity) was detected: Fe (49.939/739.15); Ca (1.715/9.16); Sr (0.270/1.98); $\operatorname{Mn}(0.129 / 1.81)$; AI (21.955/0.31); Si (23.114/0.98); Ti (1.903/20.87) and K (0.976/1.96).

The starting zeolite and clay were crushed and sieved with a selection of fractions of 63-80 microns. The zeolite was activated by ion exchange of sodium cations of the zeolite framework to cations of lanthanum and ammonium. The sorption of lanthanum ions on zeolites is accompanied by an increase in the $\mathrm{pH}$ of the equilibrium solution as a result of cationic exchange of the solution and hydrolysis of zeolites. Zeolites are subjected to the processes of decationization and dealumination. The chemical composition of activated zeolite and clay, as well as zeolite-containing composites was determined by the X-ray fluorescence method. The concentration of lanthanum in the catalysts was measured on a DFS-13 spectrograph using calibration graphs constructed using a reference sample. The phase composition of zeolite-containing composites was determined by X-ray spectral method. The measurement was carried out on a DRON-4 X-ray diffractometer equipped with an Iskra-330 control microcomputer. The value of the specific surface of the catalysts was determined by the method of thermal desorption, which allows surface measurements in the range of $0.1-500 \mathrm{~m}^{2} / \mathrm{g}$. The individual hydrocarbon composition of kerosene-gas oil fractions was determined using a HP 5890/5972 gas chromatography mass spectrometer.

In the Table 2 data on composition of catalysts made of Taizhuzgen zeolite and Narynkol clay are shown. 
Table 2: Chemical Composition of Catalysts made of Taizhuzgen Zeolite and Narynkol Clay

\begin{tabular}{|c|c|c|c|c|}
\hline $\begin{array}{c}\text { Chemical } \\
\text { Composition }\end{array}$ & $\begin{array}{l}\text { Narynkol } \\
\text { Clay }\end{array}$ & $\begin{array}{l}14 \% \text { Zeolite-Containing } \\
\text { Composite }\end{array}$ & $\begin{array}{l}20 \% \text { Zeolite-Containing } \\
\text { Composite }\end{array}$ & $\begin{array}{c}\text { Taizhuzgen } \\
\text { Zeolite }\end{array}$ \\
\hline $\mathrm{SiO}_{2}$ & 38.05 & 40.00 & 47.07 & 67.93 \\
\hline $\mathrm{CaO}$ & 20.40 & 19.77 & 15.14 & 1.97 \\
\hline $\mathrm{Al}_{2} \mathrm{O}_{3}$ & 8.49 & 9.97 & 11.51 & 14.28 \\
\hline $\mathrm{MgO}$ & 6.15 & 6.27 & 4.72 & 1.39 \\
\hline $\mathrm{Fe}_{2} \mathrm{O}_{3}$ & 4.07 & 3.75 & 4.01 & 1.79 \\
\hline $\mathrm{K}_{2} \mathrm{O}$ & 1.80 & 2.29 & 3.02 & 4.47 \\
\hline $\mathrm{Na}_{2} \mathrm{O}$ & 1.10 & $<0.50$ & 0.55 & 1.11 \\
\hline $\mathrm{TiO}_{2}$ & 0.44 & 0.23 & 0.41 & 0.29 \\
\hline $\mathrm{P}_{2} \mathrm{O}_{5}$ & 0.11 & 0.15 & 0.14 & 0.01 \\
\hline $\mathrm{MnO}$ & 0.10 & 0.15 & 0.11 & 0.04 \\
\hline Calcination Losses & 19.47 & 17.43 & 13.52 & 7.04 \\
\hline $\mathrm{La}$ & 0 & 0.20 & 0.20 & 0.24 \\
\hline
\end{tabular}

The spectra of the sample were registered on the JNN-ECA 400 spectrometer of the company "Jeol" (Japan). The operating frequency of the spectrometer is 400 and $100 \mathrm{MHz}$ on ${ }^{1} \mathrm{H}$ and ${ }^{13} \mathrm{C}$ cores, respectively. The survey was performed at room temperature using $\mathrm{CDCl}_{3}$ solvent. Chemical shifts are measured relative to the signals of residual protons or carbon atoms of deuterated chloroform. The proton spectrum of Amangeldy fuel oil contains ${ }^{1} \mathrm{H}$ signals of paraffinic, naphthenic and aromatic compounds, which are the main components of the mixture (Figure 3). Signals of methyl protons of saturated hydrocarbons (HC) are noted as a broadened singlet at $0.90 \mathrm{ppm}$. High-intensity signal with a chemical shift of $1.28 \mathrm{ppm}$ indicates a high content of protons of methylene groups of aliphatic cyclic and acyclic hydrocarbons. A small amount of $\mathrm{CH}_{3}$ groups was noted in the $\alpha$-position to the aromatic ring $(\delta=2.30-2.63 \mathrm{ppm})$. In the range of $2.70-4.50 \mathrm{ppm}$ probably the resonance of protons of the $\mathrm{CH}_{2}$ and $\mathrm{CH}$ groups in the $\alpha$-position of aromatic systems.

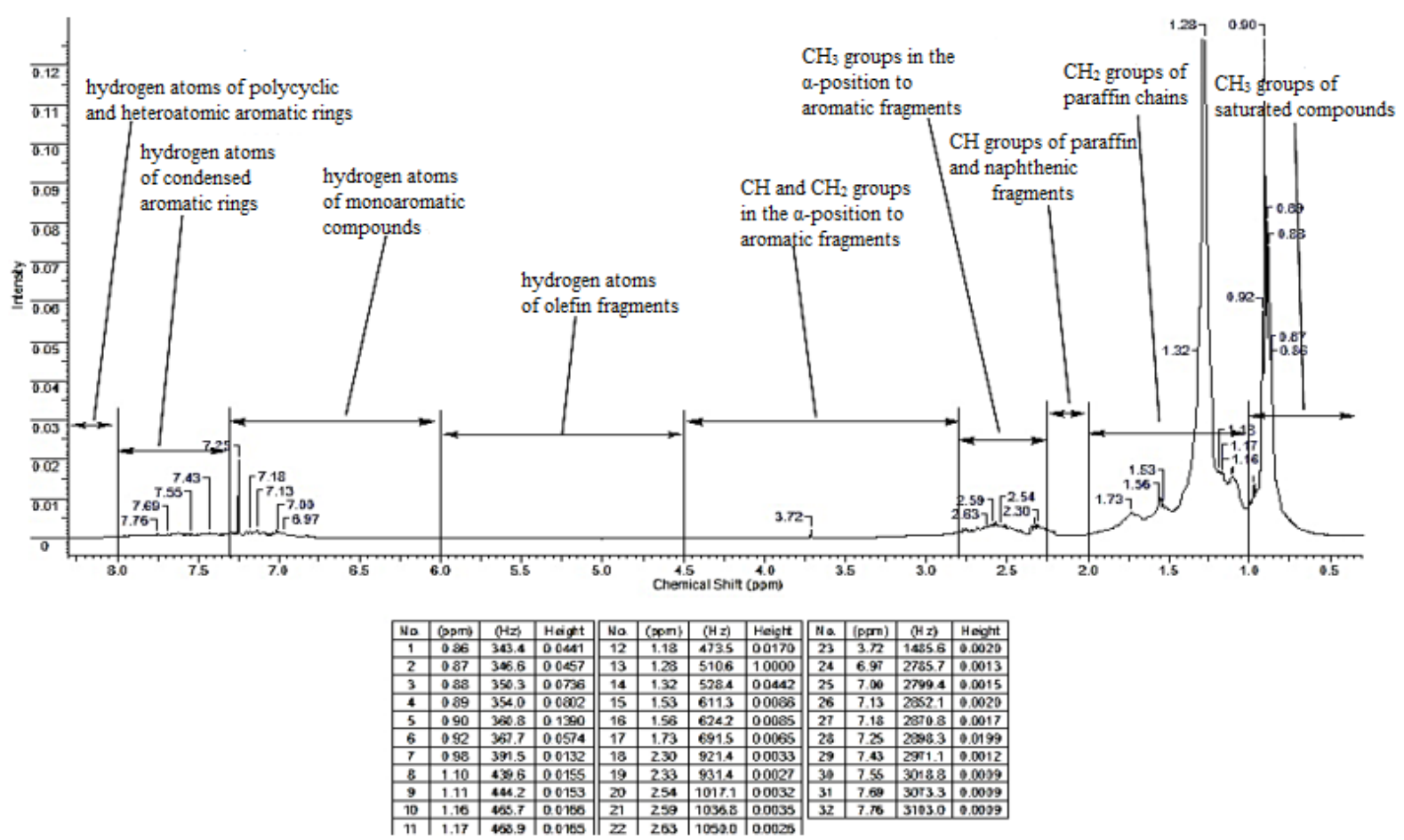

Figure 3: ${ }^{1} \mathrm{H}$ Spectrum of the Fuel Oil from the Amangeldy Gas Processing Plant. 


\section{RESULTS AND DISCUSSIONS}

The highest yield of gasoline and light gas oil is observed when air is supplied at a speed of $0.15 \mathrm{~h}^{-1}$, and an increase in the concentration of cracked raw materials suppresses the destruction of high molecular weight hydrocarbons that are part of fuel oil to light hydrocarbons of gas and gasoline fractions. The optimum temperature for fuel oil cracking at high feed rates to the reactor is $470^{\circ} \mathrm{C}$ (Table 3).

Table 3: Effect of Temperature on the Yield of Cracked Fuel Oil Product After Cracking $\left(\mathrm{W}_{\text {suspension }}=1.0 \mathrm{~h}^{-1}\right.$, Wair $=0.15 \mathrm{~h}^{-1}, 0.2 \mathrm{wt} \%$ in Raw Materials of $14 \%$ Composite $)$

\begin{tabular}{|c|c|c|c|c|c|c|c|}
\hline \multirow{2}{*}{$\mathbf{T},{ }^{\circ} \mathrm{C}$} & \multicolumn{6}{|c|}{ The Yield of Cracking Products, wt.\% } & \multirow{2}{*}{ Total } \\
\hline & Gas & Gasoline & Light Gas Oil & Heavy Residue & Coke & Losses & \\
\hline 450 & 1.1 & 3.0 & 42.7 & 51.7 & 1.5 & 0 & 100.0 \\
\hline 470 & 3.3 & 8.4 & 84.3 & 2.8 & 1.2 & 0 & 100.0 \\
\hline 500 & 2.7 & 6.4 & 73.8 & 15.5 & 1.6 & 0 & 100.0 \\
\hline
\end{tabular}

With an increase in the cracking temperature from $450^{\circ} \mathrm{C}$ to $470^{\circ} \mathrm{C}$, the yield of light gas oil doubles. Thus, in the oxidative cracking of high sulfur fuel oil in a low percentage suspension of a composite from natural raw materials, the conversion to gasoline and light gas oil is $92.7 \mathrm{wt}$.\%. This significantly exceeds the performance of known technologies for catalytic cracking of heavy oil residues (Tanimoto et al., 1998; Wang, 1979; Zhao et al., 1993). A synergistic effect is observed under conditions of the simultaneous presence of a composite catalyst and small amounts of air in the reaction zone (Table 4).

Table 4 :The Effect of the Catalyst and Air on the Cracking Process of Commercial Fuel Oil (a) and Vacuum Gas Oil Obtained from it $(b)\left(w_{\text {suspension }}=1.0 \mathrm{~h}^{-1}, 0.2 \mathrm{wt} . \%\right.$ in the Feedstock of a $14 \%$ Composite, $\mathrm{T}$ $=470^{\circ} \mathrm{C}$ )

\begin{tabular}{|c|c|c|c|c|c|c|c|c|c|c|c|}
\hline \multirow[b]{2}{*}{ No } & \multirow[b]{2}{*}{ Catalyst } & \multirow[b]{2}{*}{ wair,$h^{-1}$} & \multicolumn{8}{|c|}{ The Yield of Cracking Products, wt. \% } & \multirow[b]{2}{*}{ Total } \\
\hline & & & Gas & $\begin{array}{c}\text { Gasolin } \\
\mathrm{e}\end{array}$ & $\begin{array}{l}\text { Light Gas } \\
\text { Oil 185- } \\
340^{\circ} \mathrm{C}\end{array}$ & $\begin{array}{c}\text { Light Gas } \\
\text { Oil 340- } \\
350^{\circ} \mathrm{C}\end{array}$ & $\begin{array}{l}\text { the total } \\
\text { amount of } \\
\text { light gas oil }\end{array}$ & $\begin{array}{l}\text { Heavy } \\
\text { Residu } \\
\text { e }\end{array}$ & Coke & Losses & \\
\hline \multirow{4}{*}{$\mathrm{a}$} & $\begin{array}{l}\text { Without } \\
\text { catalyst }\end{array}$ & 0 & 1.8 & 0.8 & - & - & 12.3 & 83.7 & 1.4 & 0 & 100.0 \\
\hline & $\begin{array}{l}\text { With } \\
\text { catalyst }\end{array}$ & 0 & 2.2 & 2.1 & 11.8 & 8.4 & 20.2 & 73.9 & 1.6 & 0 & 100.0 \\
\hline & $\begin{array}{l}\text { Without } \\
\text { catalyst }\end{array}$ & 0.15 & 2.6 & 1.2 & 12.4 & 6.8 & 19.2 & 74.5 & 1.4 & 1.1 & 100.0 \\
\hline & $\begin{array}{l}\text { With } \\
\text { catalyst }\end{array}$ & 0.15 & 3.3 & 8.4 & 42.5 & 41.8 & 84.3 & 2.8 & 1.2 & 0 & 100.0 \\
\hline $\mathrm{b}$ & $\begin{array}{l}\text { With } \\
\text { catalyst }\end{array}$ & 0.15 & 8.6 & 0.2 & 28.3 & 12.9 & 41.2 & 50.0 & 0 & 0 & 100.0 \\
\hline
\end{tabular}

It should be noted that when cracking vacuum gas oil obtained from fuel oil, the yield of the kerosene-gas oil fraction is reduced by half (Table 4, b) compared to cracking under identical conditions of the original fuel oil (Table 4, a). As can be seen from Table 4(a), the composition of the kerosene-gas oil fraction of cracking products, depending on the conditions of its implementation, includes from 35.6 to $49.6 \mathrm{wt} \%$ of the fraction boiling off in the temperature range of $340-350^{\circ} \mathrm{C}$. The catalytic destruction of hydrocarbon molecules proceeds through the formation of free radicals, therefore the introduction of air, the oxygen of which is the initiator of this process, significantly increases the yield of the middle distillate fraction. 


\section{CONCLUSIONS}

- The effect of air additives in the reaction mixture on the cracking of fuel oil on a composite catalyst at a high feed rate of fuel oil has been studied.

- Commodity fuel oil and fuel oil of the M-100 brand from the Amangeldy Gas Processing Plant (Kazakhstan) were used as cracking raw materials.

- Composite catalysts were prepared on the basis of natural Kazakhstan raw materials: zeolite of the Taizhuzgen deposit and clay of the Narynkol deposit.

- It was shown that the technological parameters of the fuel oil cracking process determine the hydrocarbon composition of the resulting products.

- The air additives contribute to a deeper destruction of the hydrocarbons of the cracked feed. The highest yield of gasoline and light gas oil is observed at a speed of air $0.15 \mathrm{~h}-1$. An increase in the concentration of cracked raw materials suppresses the destruction of high molecular weight hydrocarbons (that are a part of fuel oil) to light hydrocarbons of gas and gasoline fractions.

- With the simultaneous action on the cracked molecules of the active centers of the optimal catalyst and atmospheric oxygen, a synergy was established in the yield of the middle distillate fraction.

- The results of the research on the use of activation of cracked fuel oil by dosed injection of air into the reaction zone indicate great prospects for a new direction in the catalytic processing of heavy hydrocarbon feedstocks.

\section{REFERENCES}

1. Scott, A. (2002). LG develops catalytic naphtha cracking process. J. Chemical Week, 164(21), 24.

2. Amghizar, I., Vandewalle, L. A.\& Van Geem, K. M.(2017). New Trends in Olefin Production, Engineering, 3(2), 171.

3. Delattre, C., Forissier, M., Pitault, I., Schweich, D., \& Bernard, J.R.(2001). Improvement of the microactivity test for kinetic and deactivation studies involved in catalytic cracking. Chemical Engineering Science, 56(4), 1337-1345.

4. Occelli, M. L., Landau, S. D., \& Pinnavaia, Th. J. (1984). Cracking selectivity of a delaminated clay catalyst. Journal of Catalysis, 90(2), 256-260.

5. Al-Bayati, REDHA I., SHAKEEB M. Hameed, and HIBA H. Ibraheem. "Synthesis and Characterization of New CoumarinderivativesfromPyrazolederivatives." Int. J. Appl. Nat. Sci 4.6 (2015): 35-40.

6. Dadyburjor, D.B., \& Liu, Z.Y.(1993). Selectivity and Yield of Components of a Composite Cracking Catalyst: Effect of Interactions between Composite Components. Journal of Catalysis, 141(1), 148-160.

7. Sassykova, L.R., Basheva, Zh. T., Kalykberdyev, M.K., Nurakhmetova, M., Massenova, A.T., \&Rakhmetova, K.S. (2018). The selective catalytic reactions for improvement of characteristics of gasolines. Bulgarian Chemical Communications, 50(1), 8288.

8. Jeewg, Muhsin J., Abdal-Kareem F. Hassan, and Jawad K. Zeboon. "Experimental and numerical investigation of the dynamiccharacteristic of laminated composite plate hybridwithsteel." Int. J. of General Eng. and Techn.(IJGET) 3 (2014): 1.

9. Baiseitov, D., Tulepov, M., Sassykova, L., Gabdrashova, \& Sh., Mansurov, Z. (2017). Catalytic hydrogenation of coal of the Kazakhstan fields in presence of polymers.Bulgarian Chemical Communications, 49(3), 600-607. 
10. Gomez, N., \& Molina, A. (2019). Analysis of the Particle Clustering Phenomenon in the Fluid Catalytic Cracking of Gasoil in a Downer Reactor. Chemical Engineering \& Technology, 42(6), 1293-1303.

11. Jeewg, Muhsin J., Abdal-Kareem F. Hassan, and Jawad K. Zeboon. "Experimental and numerical investigation of the dynamiccharacteristic of laminated composite plate hybridwithsteel." Int. J. of General Eng. and Techn.(IJGET) 3 (2014): 1.

12. Sassykova, L.R., Zhakirova, N.K., Aubakirov, Y.A., Sendilvelan, S., Tashmukhambetova, Z.K., Abildin, T. S., Balgysheva, B. D., Omarova, A. A., Sarybayev, M. A.\& Beisembaeva, L. K. (2020). Catalytic cracking using catalysts based on hetero polyacids. Rasayan Journal of Chemistry, 13(3), 1444-1450.

13. Liu, X., Li, Wenzhao, Xu, Hengyong\&Chen, Yanxin (2004). A comparative study of non-oxidative pyrolysis and oxidative cracking of cyclohexane to light alkenes, Fuel Processing Technology, 86(20), 151-167.

14. Pandey, Garima (2018). Nanotechnology for achieving green-economy through sustainable energy, Rasayan J. Chem., 11(3), 942-950.

15. Abul-Hamayel, M.A. (2002). Effect of Feedstocks on High-Severity Fluid Catalytic Cracking, Chemical Engineering \& Technology, 25(1), 65-70.

16. Tashmukhambetova, Zh. Kh., Zhakirova, N.K., Sassykova, L.R., Kadirbekov, K.A., Aubakirov\&Y.A., Zhumakanova, A.S.(2017). Synthesis and Study of Catalysts of Cracking on the Basis of Heteropolyacids, Oriental Journal of Chemistry, 33(6), 2803 2809.

17. Kumanan, M., et al. "Extraction of potashfrom K-Feldsparmineral by acid and moltensaltleachingprocesses." IASET Int. J. Metall. Mater. Chem. Eng 7 (2016): 1-10.

18. Guerzoni, F.N.\&Abbot, J. (1993). Catalytic Cracking of a Hydrocarbon Mixture on Combinations of HY and HZSM-5 Zeolites, Journal of Catalysis, 139(1), 289-303.

19. Redwan, D. S., \& All, S. A. (1992). Recent advances in fluid catalytic cracking process. Fuel Science and Technology International, 10(2), 141-172.

20. Akhmedzhanov, T.K., Abd Elmaksoud, A.S., Baiseit, D.K., \&Igembaev, I.B. (2012). Chemical properties of reservoirs, oil and gas of Kashagan field, southern part of pre-Caspian depression Kazakhstan. International Journal of Chemical Sciences, 10 , $568-578$.

21. Tulepov, M.I., Mansurov, Z.A., Kazakov, Yu.V., Abdrakova, F.Yu., Sultanova, Z.L., Rakhova, N. M., Madiyev, S. S., Golovchenko, O. Yu., Sassykova, L.R., Tolep, D.M., Chikhradze, N.\& Chikhradze, M.N.(2018). Methods of Reducing the Front Performance Flame at the Underground Mines Works. Oriental Journal of Chemistry, 34(6), 3037-3043.

22. Wada, K., Tada, K., Itayama, N., Kondo, T., \& Mitsudo, T. (2004). Preparation of microporous acidic oxides from aluminumbridged silsesquioxanes and catalytic activities for the cracking of hydrocarbons. Journal of Catalysis, 228(2), 374-385.

23. Lesin, V. I., Lesin, S. V., \& Ivanov, E. V.(2017). Oxidative cracking of crude oil by hydrogen peroxide in the presence of iron oxide nanoparticles. Petroleum Chemistry, 57(7), 584-588.

24. Itoh, H., Hidalgo, C.V., Hattori, T., Niwa, M.\&Murakami, Y.J.(1984). Role of acid property of various zeolites in the methanol conversion to hydrocarbons, Journal of Catalysis, 85(2), 521-526.

25. Yemelyanova, V.S., Dossumova, B.T., Shakiyeva, T.V., Sassykova, L.R., \&Sendilvelan, S. (2019). Modified aluminosilicate catalysts based on cenospheres of power plants for processing fuel oil into light fractions. International Journal of Mechanical and Production Engineering Research and Development, 9(4), 1079-1086. 
26. Lesin, S. V., \& Lesin, V. I.(2018) Mechanism of the Effect of Alternating Electromagnetic Field on Petroleum Dispersed Systems. Petroleum Chemistry, 58(7), 553-556.

27. Rigutto, S. M., Veen, R.\& Laurent, H. (2007). Zeolites in Hydrocarbon Processing, Studies in Surface Science and Catalysis, 168, 855-913.

28. Sadeghbeigi, R. (2000). Emerging Trends in Fluidized Catalytic Cracking, Fluid Catalytic Cracking Handbook, $307-337$. https://doi.org/10.1016/b978-088415289-7/50011-1.

29. Ibrasheva, R.H.\& Zhubanov, K.A.(2000). Catalytic cracking of heavy oil fractions over natural zeolite contained composites, Studies in Surface Science and Catalysis, 130, 2447-2452.

30. Ibrasheva, R.K.Mataeva, Z.T.\&Zhubanov, K.A. (2001). Oxidative Catalytic Cracking of Heavy Oil Residues, Eurasian ChemTech Journal, 3, 97-106.

31. Hamasaki, A., Yago, T.\& Wakasa, M. (2008). Magnetic Field Effect on a Radical Pair Reaction as a Probe of Microviscosity, J. Phys. Chem. B, 112 (45), 14185-14192.

32. O'Connor, P. (2007). Chapter 15 Catalytic cracking: The Future of an Evolving Process, Studies in Surface Science and Catalysis, 166, 227-251.

33. Omarova, A., Sassykova, L., Tulepov, M.\&Zhakirova, N. (2019). Study of non-hydrogen transformation of model n-alkanes and a diesel fraction over La-Zn-Mn/Al2O3+ZSM-catalyst, Journal of Chemical Technology and Metallurgy, 54(3), 547-554.

34. Stocker, M. (2005). Gas phase catalysis by zeolites. Microporous and Mesoporous Materials, 82, 257-292.

35. Tuktin, B.T., Tenizbayeva, A.S., Omarova, A.A., Sassykova, L.R.\&Sailau, Zh.A. (2019). Hydrofining of petrol fractions of oil on modified alumina catalysts, Rasayan J. Chem., 12(3), 1478-1484.

36. Brueva, T.R., Mishin, I.V., \& Kapustin, G.I. (2001). Distribution of acid-site strengths in hydrogen zeolites and relationship between acidity and catalytic activity. Thermochimica Acta, 379, 15-23.

37. Tanimoto, Y., Tanaka, H., Fujiwara, Y.\&Fujiwara, M. (1998). Effects of High Magnetic Field on the Lifetime of Chain-Linked Triplet Biradicals Composed of Xanthone Ketyl and Xanthenyl Radicals, J. Phys. Chem. A, 102 (28), 5611-5615.

38. Wang, I. (1979). The comparison of cracking activity, product selectivity, and steam stability of ZSM-5 to other cracking catalysts. Journal of Catalysis, 60(1), 140-147.

39. Zhao, Y.X., Bamwenda, G.R., \&Wojciechowski, B.W.(1993). Cracking Selectivity Patterns in the Presence of Chain Mechanisms. The Cracking of 2-Methylpentane. Journal of Catalysis, 142(2), 465-489.

\section{ACKNOWLEDGEMENT}

We would like to express sincere gratitude for grant financing by the program: No. BR05236634 "Development of a technology for the production of new multifunctional porous magnetically controlled nanoscale materials based on cenospheres of fly ash for immobilization, curing and neutralization of radiation waste". 


\section{AUTHOR'S PROFILE}

\section{T.V. Shakiyeva}

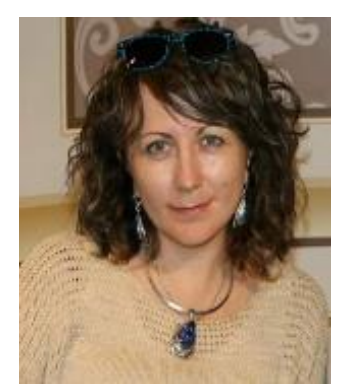

T.V. Shakiyeva, PhD, Leading Researcher of the Scientific and Production Technical Center "Zhalyn" LLP. She graduated from the Faculty of Chemistry and Chemical Technology of the al-Farabi Kazakh National University (Specialty "Chemistry", honors degree) and the postgraduate course at the al-FarabiKazNU (Almaty, Kazakhstan). Areas of scientific interests are: chemistry, chemical technology, catalysis, ecology. She was awarded prizes and a state grant of the Republic of Kazakhstan for young talented chemists of Kazakhstan. She published ca. 250 publications, including papers and patents of the RK.

\section{B.T. Dossumova}

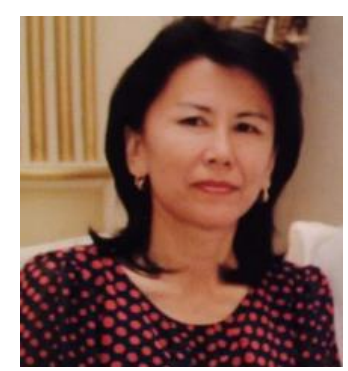

B.T. Dossumova, PhD, Leading Researcher of the Scientific and Production Technical Center "Zhalyn" LLP. She graduated from the Faculty of Chemistry and Chemical Technology of the al-Farabi Kazakh National University (Specialty "Chemistry", honors degree) and the postgraduate course at the D.V. Sokolsky Institute of Organic Catalysis and Electrochemistry, Specialty "Chemical Kinetics and Catalysis" (Almaty, Kazakhstan). Areas of scientific interests are: chemistry, chemical technology, catalysis, ecology. She was awarded prizes and a state grant of the Republic of Kazakhstan for young talented chemists of Kazakhstan. She published ca. 250 publications, including papers and patents of the RK.

\section{L.R. Sassykova}

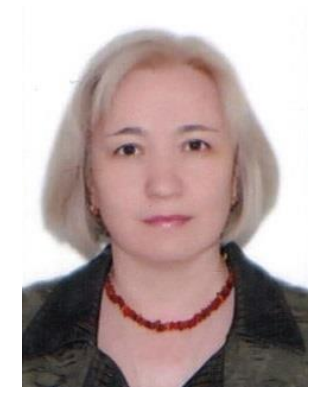


L. R. Sassykova, Prof. of the Department of Physical Chemistry, Catalysis and Petrochemistry at the al-Farabi Kazakh National University. She graduated from the Faculty of Chemistry and Chemical Technology of the al-FarabiKazNU (Specialty "Chemistry", honors degree) and the postgraduate course at the D.V. Sokolsky Institute of Organic Catalysis and Electrochemistry, Specialty "Chemical Kinetics and Catalysis" (Almaty, Kazakhstan). Areas of scientific interests are: chemistry, chemical technology, catalysis, ecology. She published ca. 400 publications, including papers, educational manuals, monographs and patents of the RK. Hirsch index 12.L.R. Sassykova was awarded the title "The best teacher of the University" of the Republic of Kazakhstan (2019).

\section{N.B. Zhakirova}

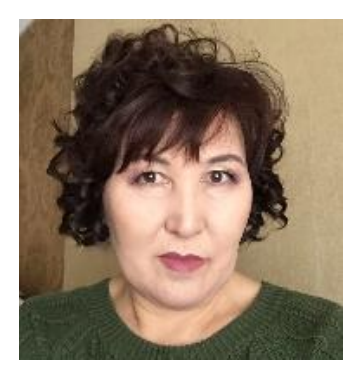

N.B. Zhakirova, PhD, Associate Professor of the Department of Physical Chemistry, Catalysis and Petrochemistry at the al-Farabi Kazakh National University. She graduated from the Faculty of Chemistry and Chemical Technology of the alFarabiKazNU (Specialty "Chemistry", honors degree). Areas of scientific interests are chemical technology of inorganic substances, geoecology, analytical chemistry. She was the executor of numerous Republican scientific projects. She has more than 150 publications, including educational manuals, monographs and patents of the Republic of Kazakhstan. Her educational manual "Chemical Analysis" was awarded the prize. Hirsch index 5. 

